\title{
Research on the Status of SMEs of Ya'an in the Internal Control
}

\author{
Qiu Xiao \\ College of Economics \&Management, University of Sichuan Agriculture \\ 211 Hui Min Road, Wen Jiang 611130, China \\ Tel: +86-135-5034-2470Ｅ-mail: xiaoqiupurple@126.com
}

Received: August 1, $2011 \quad$ Accepted: August 23, 2011 doi:10.5430/jms.v2n3p86

\begin{abstract}
After visiting some SEMs and conducting a questionnaire survey of them, the author used the descriptive statistical analysis to analyse the data and found that SEMs emphasized the impacts of the external environment, the construction of the internal control system, and the control of the business links, the currency and assets. But meanwhile, the SEMs ignored the establishment of the enterprise culture, the coordination of the whole enterprise, the containment of the links and positions, and the improvement of the quality of the ones that carried out the internal control system. Enterprises could improve the situation of the internal control by effective division of responsibilities, using the electronic imformation tools, arranging internal audit staff, managers lead by example, enhancing staff skills training to improve their quality, establishing special institutions, improving incentives and accountability of major system and other measures.
\end{abstract}

Keywords: Internal Control, SME, the Status

Internal control refers to the level of governance by the corporate decision-making, management and implementation of all employees, designed to provide reasonable assurance of business management, legal compliance, asset security, financial reports and true and complete related information, to improve operational efficiency, and to promote enterprise development strategy. Establishing and implementing a sound internal control system could plug a variety of loopholes in business activities, strengthen management and supervision of internal control, make us pay more attention to internal control evaluation of reward and punishment, improve enterprise management level, and promote healthy and sustainable development. The paper is made of the internal control deficiencies, three major issues of internal control, the inherent limitations of internal control and other aspects with the information from the survey.

\section{Deficiencies of SEMs in the Internal Control System}

Implementation of internal controls is deep into all aspects of manufacturing operations, strengthening internal control means to create benefits for the manufacturing operations. Enterprises should intensify the supervision of internal control, transformation, implementation when they improve their business efficiency. Through the survey, we found that SEMs had the following internal control deficiencies.

\subsection{Unreasonable Organization}

Unreasonable organization mainly reflects in the organizational setting, the scientific division of the department's responsibility, personnel quality control and so on. When we set the internal organization, if the needs of work and the needs of internal controls are not compatible, it will make the institutional setting bloated and complex, lack of internal checks and balances, and make the corporate governance structure imcomplete and hard to meet the requirements of modern enterprise system either.

\subsection{Lack of Risk Control}

Enterprises can not ensure the healthy operation of the management activities if the management do not have risk awareness or do any risk research, not to speak of internal control, effective risk control system, emergency response plan for emergencies or value of internal controls. If so, it would be difficult to guarantee the corporate assets.

\subsection{Non-Standardized Internal Audit}

Part of the internal audit were not standard, some even did not have the accounting audit department. Internal audit staffs were responsible for directors and managers, many companies ignored the role of internal audit, many internal auditors were part-time, or just kept a close watch of a business, making the internal audit not a regulatory role. 


\subsection{Lack of Execution Control}

Although some enterprises had built the appropriate rules and regulations, but they were shelved and become a mere formality. Therefore the implementation or execution was not in place, issues such as low performance monitoring mechanisms were in common.

\section{Three Major Issues of Internal Control}

\subsection{Contempt or Neglect Of Internal Control}

Most of China's enterprises relied on their own grasp of the market and the individual spirit of adventure to complete the primitive accumulation of capital, they paid attention only to market, and were not familiar with accounting or even did not pay attention to that. Value of existence of accounting in the enterprise depended on whether or how to escape as much tax as possible. Meanwhile, expenditure without permission, IOUs and even illegal accounts were common occurrences, and some even transacted the current book secretly and put the cash into the cashier deposited in the name of cashier in order to draw money easily.

\subsection{Weak Implementation of Internal Control}

Few of the enterprises can execute the internal control system strictly despite of the good internal control system because of the fuzzy property rights. The appearance of "Zhengbaiwen", who adjusted profit growth, showed us that owing the internal control system did not mean good business operations. The improvement of the internal control mechanisms could ensure the effective implementation of the system to a certain extent, and regularly tests were more important for us to make appropriate adjustments. Enterprises would consider listing the company to a certain stage of development and developing a formalized internal control system because of an urgent requirement of listing, but the emptiness of the long-standing internal control situation had been normalized, making it difficult to implement the sound internal control system. The sharply increase of the operating costs when running internal control system, which were based on market demand, and the lag of the operating environment of existing internal control gave birth to false to some degree.

\subsection{Well-Designed Pseudo-Control}

The relevant documents that Yinguangxia owned were available on the surface examination, approval and other control links were also very complete, and in order to achieve profits or other purposes, Yinguangxia designed pseudo-control well to deceive inventors. The situation would be more and more with the development of China's capital market.

\section{Inherent Limitations of Internal Control}

Deficiencies or failure of some aspects in internal control were caused mainly by subjective reasons of business leaders, partly by the objective reasons during the production process, but there were also inherent and inevitable limitations in the following areas.

\subsection{Oversight of System And Human Error}

As the system is made and implemented by people, the internal control system was difficult to achieve hundred percent thorough because of the limitations by vision and ability level. Design defects and other causes can lead to staff separation constraints and decisions on major issues without standards. The existing internal control system are designed generally for recurring business, lack of control of the unforeseen business and unconventional projects, also in lack of insight, knowledge of a broad range of economic management and risk management. In addition, the system implementation process could be biased inevitably. Failure of internal control could be led to if there are careless implementation, misjudgment, leadership authority and misunderstanding of instructions, performing without necessary authority and operation defects because of running against the design intent.

\subsection{Cost-Effective Constraints}

We had to put human, material and financial resources into internal control as cost, but we could reduce risk of production instead of spending more. As the market economy continued to standardize, developing the internal control system would become more complex and robust, and then internal control costs would be higher. For cost-effectiveness considerations, separation of system design and job responsibilities in enterprises may be not in place.

\subsection{Collusion}

In and between the enterprise sectors, there was a clear division of labor, but if they colluded with each other and did acts that violated the rules, it would be more terrible than no system and brought immeasurable loss and damage to the enterprises. Directors of the machine manufacturers materials, directors of comprehensive and directors of storage, heads of waste recycling owners, planners and others in the China Aerospace Science and Industry Group, Liuzhou Changhong, complicit in the use of his position from 2001 to 2002 and brought serious damage to the business interests. 


\subsection{Lag of System}

Internal control might need to revise and improve the existing system because of the changes of the operating environment and the characters of the business. If the amendment was not timely, it would be out of touch with changes of the environment.

\subsection{Management Override}

Those business leaders abused their power, went above the system, exceeded their duties to examine or approve, would enable enterprises to form a "vacuum" of supervision and management and bring a serious impact on business. Once abuse of power formed, it would destroy the seriousness and authority of the system.

To make the conclusions of this survey more universal and representative, The author conducted interviews and random surveys, the results showed that the enterprises surveyed recognized the importance of internal controls in common, but the understanding of that was not enough, SEMs emphasized the impacts of the external environment, the construction of the internal control system, and the control of the business links, the currency and assets, but ignored the establishment of the enterprise culture, the coordination of the whole enterprise, the containment of the links and positions, and the improvement of the quality of the ones that carried out the internal control system.

\section{Data Analysis}

\subsection{Relations of the Respondents And Enterprises}

Most of the people surveyed were staff, their sense of belonging for the work unit was weak, and they were lack of security when working. When asked how familiar they knew the workflow, up to 35\% of the people did not know well. Over 50\% people's answers showed that corporate decision-making power was too concentrated, employee participation rights were denied.

\subsection{Staff Management}

The survey found that there were appraisal system over $90 \%$ of enterprises, but appraisal system had not been strictly enforced. More than $70 \%$ of the company would conduct pre-job training. At the same time, the survey showed that $80 \%$ of the enterprises had a clear division of responsibilities; it was not allowed to substitute for others freely when working.

\subsection{Inventory Control}

The survey showed that more than $75 \%$ of enterprises would check and make notes in the inventory before the inventory got in the storage, up to $80 \%$ of the enterprises would conduct a detailed inventory before the inventory got out of the storage, about $5 \%$ of the enterprises would not perform such procedures, and nearly $12 \%$ of companies surveyed did not know whether the enterprises would check the number, variety, size or other aspects of inventory when inventory getting in and out of the storage or not.

\subsection{Control of Economic Operations}

$88 \%$ of companies required that heads of the relevant departments should sign when a relevant economic business occurred. And it was said that $66 \%$ of the signatories were the business manager or business leader.

\subsection{Overall Grasp of the Funds}

Survey showed that nearly $72 \%$ of people would conduct business detailed accounts regularly and detailed, while $8 \%$ of enterprises did not do so, in addition to $20 \%$ of employees did not know such work of the companies in these areas. Survey also showed that $80 \%$ of the corporate accounting staff worker and cashier were in separation. As to the grasp of an account, the survey showed that $55 \%$ of business units would check accounts, especially large amount of economic business, with customers. At the same time, nearly $20 \%$ of companies did not know these works, and even $17 \%$ of people said that enterprises would not carry out such work. In addition, the survey showed that only $75 \%$ of the enterprises would register in the account book timely, accurately and properly when every business work occurred.

\subsection{Grasp of The Customer Relationship}

According to the survey, $63.54 \%$ of companies had no major disputes with their clients in business. In the enterprises where there were business disputes, 60 percent of companies had chosen to bear he primary responsibility, 8.33\% of the companies chose to ask the corporate customers for responsibility-undertaking, and another 31 percent of companies did not know how to deal with such situations. 


\section{Suggestions}

5.1 Setting up Special Agencies to Manage, Improving and Implementing the Revised System of Internal Control Continuously, Effectively and Strictly

Establish the special management agency, allocate dedicated managers, and if necessary, draw support from the experts when facing new changes of the corporate internal and external environment. Strengthen risk assessment, revise and consummate the internal control system timely, track and supervise the execution results of the internal control system regularly and irregularly, and appraisal the effectiveness of the internal control system.

\subsection{Consummating Incentive Mechanism and Major Responsibilities Chasing System}

The key to make the internal control system effective is to establish practical evaluation and incentive mechanism. Establish a scientific and reasonable evaluation of internal control standards, consummate the award-punishment mechanism of the internal control system, make the evaluation have its own rules and then enhance the activity of operation. As to the significant internal control issues arising in the course of accountability, the problems must be corrected immediately when found, persons who are responsible for those should be punished, those who violate law must be transferred to judicial organs with no mercy, and the department or individuals that adopt the strict implementation of the internal control system should be given spiritual and material rewards.

\subsection{Detailed Division of Responsibilities, Strengthen the "Internal Restraints" to Prevent Fraud}

As an internal restraint mechanism, internal control aims to balance the fixed rights within the company, coordinating owners, managers, and employees to make them effectively perform their duties. Companies must separate the duties which if the same person holds the posts, errors and fraud might appear and be covered up by him. Each class of economic business must be run in different departments and be checked by the relevant departments. In each inspection of the economic operation, the examiner should not be subordinate to inspected department, so that effective checks and balances would come true to ensure that people in incompatible duties and posts could supervise and restrict each other.

\subsection{Making Internal Controls Electronized And Informationized}

Companies should combine their actual situation, keep close collaboration with software development companies, make risk prevention capabilities of restrict and supervision into various software operating procedures in order that the relevant approval and the operator must follow the prescribed functions and powers to enter the system for approval and treatment-related businesses. Pay attention to crime prevention and computer technology risk, improve data input, modify, review, approval of internal control to ensure the effective operation of internal control, change artificial management, man-made control for the computer and network management and control and protect electronic information systems and network security.

\subsection{Staffing Internal Audit, Implementing Supervision Functions Effectively}

Enterprises must foster risk awareness and establish risk culture, enrich the audit team, have them separated from the financial and accounting departments, make them carry out various special audit activities irregularly, and be responsible directly for corporate decision-making layer. Strengthen the company's audit executive-level of internal control and supervision, especially in key positions and management personnel of the audit and supervision.

\subsection{Managers Lead by Example}

Corporate management must play their leading role to convince the employees and enable enterprises to develop sustainably and healthily. Among the constituent elements of the internal control environment, the corporate governance and management level are the most important factors, only if the layer of governance and management lead by example, set a good example and establish the correct orientation of values and ethics, internal controls would be consolidated and strengthened.

\subsection{Enhance Staff Skills Training, Improve Staff Quality}

Strengthen ideological and moral standards training of staff, make employees understand that the business benefits are no small matters, know self-discipline, and have the courage to expose the individual misdeeds. At last, have full participation in the internal control system construction and implementation. Strengthen the full practical operation learning and training of internal control system, eliminate all kinds of occupation and misappropriation of corporate assets, and reap improper behavior to obtain benefits. 


\section{References}

Liming Yang.(2010). The internal control framework of the three-dimensional theory buildiing. Accounting magazine, 9, 8-10.

Meiying Wang and Xiaorong Zheng.(2010). Discussion on Internal Control Audit of Small Business. China Certified Public Accountants, 7, 55-57.

Ruiping Yang.(2010). Explore of issues related to internal control audits. Business Research, 4, 63-67.

Shengming Tang(2010). Optimize the internal control environment, regulate the internal control. Financial supervision, 12, 52-53.

Wenhan Meng and Fanrong Zeng.(2010). Analysis of the internal control system in Information Environment. Friends of Accounting (early), 3, 16-18.

Xiaoyan Xie, Longping Zhang and Yuan Zhou.(2009). Internal control audit research: literature review. Accounting, 36, $125-128+161$.

Yibing Wu.(2009). The internal control audit, value relevance and cost of capital. Economic Management, 9, 64-69.

Yongping Liu.(2009). Internal controls and business risk prevention. Friends of Accounting (late), 10, 45-46.

Yongqing Guo and Wei Gao.(2009). The design of internal control integrated framework. China Certified Public Accountants, 6, 29-32. 